\title{
Interactions between disciplinary practice and joint work in undergraduate physics research experiences
}

\author{
Gina M. Quan \\ Center for STEM Learning, University of Colorado Boulder, 393 UCB Boulder, Colorado 80309, USA \\ Chandra Turpen ${ }^{\dagger}$ and Andrew Elby \\ Department of Physics, University of Maryland, College Park, 082 Regents Drive, \\ College Park, Maryland 20742, USA
}

(Received 8 March 2017; revised manuscript received 28 November 2017; published 7 December 2018; corrected 22 May 2019)

\begin{abstract}
We analyze how participating in undergraduate research experiences (UREs) influenced physics students' trajectories of participation within the community of practice of physics researchers. Students in the study participated in an elective seminar in which they were paired with graduate student and faculty mentors on physics research projects and participated in weekly discussions about research. Using video data from student interviews and mentor interviews, we characterize two aspects of students' engagement in the physics community of practice. First, we find variations in their engagement in physics practice, which we characterize as physics activities that are connected and purposeful. Second, we characterize forms of joint work by the research project's form and structure and by patterns of interaction between undergraduates and mentors. We argue that forms of joint work influenced students' varied senses of how physics activities are connected and purposeful. Finally, we use this understanding to suggest how to better scaffold UREs.
\end{abstract}

DOI: 10.1103/PhysRevPhysEducRes.14.020124

\section{INTRODUCTION}

Physics as a field often emphasizes the value of undergraduate research experiences (UREs) [1], describing them as "authentic" and "real" science in relation to standard coursework [2]. UREs have been shown to increase retention in science, technology, engineering, and math (STEM) fields, particularly for students from underrepresented backgrounds [2]. However, implicit within these recommendations are assumptions about what counts as authentic physics. Within our work, we put forth one framework for characterizing "authenticity" in physics research, with the aim of understanding how students are supported in —or cut off from-engagement in physics practice.

We developed a seminar at the University of Maryland, College Park with the intention of fostering new pathways into physics through giving students the opportunity to participate in research experiences. Any student who was interested in research but was not currently doing research

\footnotetext{
*gina.m.quan@gmail.com

turpen@umd.edu

†elby@umd.edu
}

Published by the American Physical Society under the terms of the Creative Commons Attribution 4.0 International license. Further distribution of this work must maintain attribution to the author(s) and the published article's title, journal citation, and DOI. was encouraged to enroll during advising. This course is part of the Equity Constellation (formerly known as Focus on Physics) program in the Maryland Physics Department, which is one of nine inclusiveness-focused programs in the Access Network. The design of the seminar aligned with core values of the Access Network, including adopting a "whole person" approach [3,4], which involved community building and explicitly discussing students' struggles and senses of belonging as they connected to physics. The seminar was paired with ongoing research with outside mentors, giving students the opportunity to participate in more authentic physics activities than is often found in traditional coursework. Through these activities, we hoped to (i) expand the set of pathways toward becoming a scientist by refining students' understanding of what science is and (ii) support students in seeing themselves along such pathways.

Our research on this setting studies how the research experiences afforded shifts in students' participation in physics. Our approach integrated several dimensions of students' participation - shifts in their knowledge of physics and physics research, shifts in their abilities and skills, and shifts in how they saw themselves and were recognized by others as doers of physics. This paper focuses on one thread of this work, looking at whether students came to participate in physics practice.

We define physics practice as a set of physics activities that are connected to one another and work together toward 
a scientific purpose. We then studied how engagement in physics practice was impacted by joint work with their research mentors. Joint work refers to the work within research groups in which members depend on one another to achieve an outcome. Joint work can take many forms, including working in the same space on the same task, and working asynchronously on different tasks. We found that the forms of joint work impacted the extent to which students experienced the connectedness and purposefulness of scientific activities.

Within this paper, we study how joint work impacted students' experiences of connectedness and purposefulness of scientific activities within three cases. We selected these cases to purposefully represent different degrees of connectedness and purposefulness. Our purpose in this paper is not to develop claims about how these results might generalize to different populations of students.

\section{BACKGROUND}

Prior research on undergraduate research experiences (UREs) suggests that UREs can have numerous positive outcomes, including the development of content knowledge, research skills, productive beliefs about physics, and disciplinary identities [5-9]. Research experiences can also support students' persistence in STEM fields $[2,10,11]$. This work informs a wide set of national recommendations to increase the number of students participating in UREs $[2,12]$.

Much of this work has identified and categorized the specific scientific activities in which students engage. A study by Hunter et al. describes student gains from doing research [6,13]. Their category Gains in understanding science research through hands-on experience includes items such as problem solving, analyzing, and interpreting results and Gains in communication skills includes items such as presentations, writing, and laboratory or field techniques. Similarly, the undergraduate research questionnaire (URQ) $[7,14]$ subscale research methods probes for whether or not students engage in individual research activities:

\section{I can design experiments. \\ I can troubleshoot experiments. \\ I understand how to report experimental results. \\ Generating hypotheses is something I can do. \\ Data analysis is something I can do. \\ Carrying out experiments is something I can do.}

This body of work illustrates the breadth of activities that students in UREs engage in. These activities often differ from those found in traditional lab courses [15].

Prior work has shown that mentorship impacts what students get out of research experiences. Mentors who spend more time with the mentee, are enthusiastic and engaging, and make themselves more available tend to be associated with greater learning gains and identity development $[7,13,16]$. Byars-Winston et al. found that specific mentoring activities such as giving constructive feedback and helping mentees place their research in terms of a larger project impacted students' self-efficacy [17]. Thiry and Laursen identified three domains of mentor support: professional socialization (the disciplinary norms and knowledge), intellectual support (knowledge needed to complete the specific project), and personal/emotional support (being supportive and available) [18]. The professional socialization encompasses mentors helping students understand how their project fits into the broader discipline. Other quantitative research has found small but statistically significant correlations between students' learning outcomes and mentorship characteristics (e.g., perceived quality); these authors argue that the weakness of the correlation is due to the complexity of mentoring relationships, and they recommend further study on the impact of research mentors [8,19]. Harsh, Maltese and Tai argue that a "colleague model" of mentorship, characterized by collaboration between students and mentors, is more beneficial than when mentees are delegated more simple tasks [20,21]. However, while these studies have articulated features of productive mentorship, they characterize mentoring activities at a coarse grain size, such as number of interactions $[16,20,22]$, perceived quality of mentorship $[8,19]$, level of autonomy [21], and potential outcomes [18]. More research is needed, however, to determine what the day-to-day activities of a research experience look like, and how those impact what students get out of doing research.

In summary, prior research has identified many positive outcomes of UREs, including naming the scientific skills students develop and activities students engage in, and has started to identify consequential features of mentoring relationships that lead to positive outcomes. However, we argue that much of the work on UREs treats scientific activities in reductionist ways by quantifying isolated skillbased outcomes and characterizing experiences as more positive when students engage in more of these activities $[5,7,8,13]$. These items do not capture students' understandings of why these activities are important to science or their relationship to other scientific activities. For example, consider the following URQ item:

\section{I understand how to report experimental results.}

We agree that presenting and reporting on experimental results is an important aspect of science, and at a coarsegrained level it can be important to know how many students engage in this activity. However, we see the presentation of scientific results as meaningful because presenting ideas is important toward a community's refinement of scientific ideas. This item also does not assess whether students are able to judge the appropriateness of 
such a presentation or see how that activity is meaningfully connected to the other activities that led to the presentation. A similar case is made by Linn et al. who argue that ideas learned in UREs are typically viewed by students as isolated, and mentors need to explicitly connect them to students' existing knowledge and understanding of activities [22].

Instead of looking at doing science as a set of skills and activities, we argue for a focus on scientific practice. A scientific practice is a set of activities that are embedded within and work toward the aims of a scientific community [23]. For any given scientific community (e.g., a science classroom, physics researchers), members determine what counts as valuable forms of scientific knowledge within that community, and, consequently, what counts as serving the community's aims. So, from the student's perspective, a "skill" or "activity" is part of practice to the extent that the student sees how the skill or activity meshes with other skills or activities and whether the set of activities serves a scientific purpose. We adopt a practice focus for two reasons: (i) The intuitive sense that doing science is more than just the enactment of certain kinds of knowledge and skills; engaging in science also relies on seeing how each component is meaningfully connected and embedded within a scientific purpose, and (ii) our commitment to viewing learning as a process of legitimate peripheral participation [24,25], in which learning is not reducible to the accumulation of specific skills and knowledge. This communities of practice approach has not yet been applied to look at how the structure of research activities and project work impacts participation in physics practice.

We start by asking, what does it look like for newcomers in physics research to come to engage in physics practice? We focus on two aspects of participation that Lave and Wenger highlight as important aspects of participation in all communities of practice [24]: (i) engagement in the practice (in this case, physics practice), and (ii) interactions between less experienced and more experienced community members (in this case, students and mentors), which we call joint work. To study engagement in physics practice, we use a framework from Ford [26] which defines a scientific practice as a set of activities which are connected to one another and to a scientific purpose. To study joint work, we look at the form and structure of the research projects, as well as the patterns of interaction between mentors and students. Our approach illustrates how the organization of activities and project work impacts students' learning of the connectedness and purposefulness of their work. In our discussion, we use this understanding to suggest how to better scaffold UREs to enable deeper participation in physics practice.

\section{THEORETICAL PERSPECTIVE}

In this section, we discuss our theoretical perspective for this work. We first discuss viewing learning as a process of legitimate peripheral participation within a community of practice. Because this framework has been used to conceptualize learning in many kinds of communities, we elaborate on our conceptualization of the discipline-specific aspects of the physics research community of practice. To do this, we use a framework from Ford to conceptualize engagement in physics practice, which is defined by activities that are meaningfully connected to one another and to a scientific purpose.

\section{A. Legitimate peripheral participation}

As conceptualized by Lave and Wenger, situated learning theory describes learning as the process of shifting participation within a community of practice [24]. A community of practice is a set of people who work together on shared activities toward a set of shared goals. Wenger refers these shared goals as the community's "joint enterprise" [25]. Within a community of practice, legitimate peripheral participation (LPP) refers to the process of novices learning through engaging in joint work with experts [24]. Depending on the form and structure of these activities, they can facilitate deeper understanding of the community and more central engagement in the practice of the community. Membership within the community is complex; there are a diversity of ways to participate, and similarly a diversity of ways that participation shifts. The processes of learning and identity development are directly intertwined with one's shifting participation.

The process of shifting participation within a community of practice is neither a linear nor smooth process. Interactions with other members of the community can lead to participating more centrally or peripherally in the practice. Who one is and how one engages in a disciplinary practice is dependent on the form and nature of the joint activities and interactions with others. This perspective has been used by other scholars in physics education research (PER) and science education to describe how learning is impacted by contextual features of learning settings, such as aspects of a student community and classroom supports and structures [27-30].

Within our work, we conceptualize the physics research community as a community of practice. A central goal of the physics research community is to advance the understanding of nature through creating coherent causal explanations of physical phenomena. The community itself is broad and distributed. Roles and responsibilities vary across subfields, research groups, and within research groups. Moreover, within subdisciplines of physics, the kinds of epistemic approaches and commitments vary [31]. We define the epistemic approach to be the use of different research approaches, and the logic underlying how a research approach leads to generation of knowledge. An epistemic approach is similar to what Kelly refers to as an "argumentative grammar...the logic that guides the use of a method and that supports reasoning about its data" [32]. 
We expect differences in each student's trajectory in the physics research community depending on their subfield, project, and interactions with other members of the community. For example, a research experience in a large collaboration would differ from a research experience using tabletop experiments, in terms of division of labor and which activities are prominent. Even the enactment of the same activities, such as engaging in critique or crafting a scientific publication, would look different in the two settings. We choose to focus on students' perspectives on their participation with the community of physics researchers because these will likely impact students' long-term relationships to physics. It is also likely that their perspectives may differ from others' perspectives (including research mentors' perspectives). Comparing students' and mentors' perspectives would be a fruitful avenue for future work.

\section{B. Joint work}

Literature from interaction analysis informs our use of the term joint work to characterize research activities in UREs. Barron first described joint work as collaborative problem-solving undertaken by children solving math problems. Barron identified multiple forms of joint work, taking into account students' social interactions and disciplinary engagement $[33,34]$. These forms of joint work may or may not have the following features: shared task alignment (a "collaborative orientation to problem solving" which includes building off of one another's ideas), joint attention (such as toward a workbook or other artifact), and mutuality (the potential for all members to contribute). While this research focused on children's problem solving, we find that this work gives us a language for describing forms of engagement in research groups. Some joint work in a research group might look like what Barron calls coordinated co-construction (characterized by shared task alignment, joint attention, and mutuality) where students meaningfully contribute ideas in dialogue with mentors on a joint task. A research project in which a mentor delegates tasks, and the mentee works with little monitoring or feedback would have little shared task alignment or joint attention. Our approach differs structurally from Barron's in two ways: (i) our data about each participant's engagement in joint work in their lab comes from interviews with participants, and (ii) Barron studied novice-novice collaborations while we studied expert-novice collaborations. However, we find that Barron's characterizations of different forms of joint work help us name important aspects of patterns of interaction and project structure across research groups. We elaborate on this in our analytical approach in Sec. IV.

In a similar vein, Kirshner [35] identified several forms of guided participation between youths and mentors in youth activism groups. Kirshner defined joint work to be a form of guided participation in which mentors and youth worked on a project identified by a mentor. This contrasts different forms of guided participation where projects are responsive to students' interests or where mentors do not participate in the project activities at all. While Kirshner's definition of joint work is more narrow than Barron's (and ours), the mentorship that we observed in 299B fit Kirshner's definition of joint work. In all research projects, students worked on a project designed by a mentor, and mentors participated in project activities.

In summary, we align our definition of joint work with Barron's, which broadly encompasses various types of collaborative problem solving. We acknowledge that the term "joint" may be misleading; this does not necessarily imply that members maintain joint attention and shared task alignment. Rather, the work is joint in the sense that it requires social orchestration, that members know their role in the activity, and that members depend on one another to achieve an outcome. While we use the term joint work, we do not mean for joint to obscure the power dynamic that exists between mentors and mentees. Rather, we align our perspective with Rogoff's notion of a community of learners [36], in which learning between more and less mature members of a community is inherently asymmetric. In this model, all participants play an active role, but more mature members guide the direction of the activities.

We now turn to prior work on disciplinary practice to describe how we are analyzing practice in this paper.

\section{Disciplinary practice}

We conceptualize a scientific practice as a set of activities that are embedded within and work toward the aims of a scientific community [23]. Within a practice, activities are also logically coherent with respect to other activities (Berland et al. refer to this as an "ensemble of activity." [37]). For example, the activity of conducting an experiment is considered part of a "practice" if the experiment is connected to a driving question about a phenomenon and to a sensible method of analyzing the data that leads to knowledge generation for the community in which the question is embedded. It would not be considered part of a practice if it was done as an isolated activity, independent of the underlying logic of how the experiment (in concert with other activities) would produce knowledge valuable to the community. Thus, the extent to which an activity is part of a scientific practice is dependent on how it is perceived to be embedded within the ensemble of activities and goals of the community.

Whether or not an activity "works toward the aims of a scientific community" is dependent on the community in which the activity is embedded. For example, within a science classroom, students generate scientific questions and develop a coherent set of activities that allow them to answer those questions. We label those activities as scientific practice when they "toward the aims of a scientific [classroom] community" [37]. What counts as 
practice within a science classroom community differs from what counts as practice within the community of physics researchers. Within a community of physics researchers, physics research practice necessarily works toward answering questions in which that the physics research community is invested.

While we choose to not label isolated activities as "scientific practice," we are not claiming that such activities are unproductive for students. In principle, learning such isolated activities can still be educational and prepare students for future participation in scientific practice. However, an activities' embeddedness within this ensemble of activities is what makes it scientific practice in addition to a productive learning opportunity.

We apply a framework from Ford [26] who draws on work by Rouse [38] to define a scientific practice. Ford conceptualizes practice using the Next Generation Science Standards (NGSS), which outlines several activities (which they label as practices) for K-12 (e.g., modeling, formulating questions). Ford argues that the purpose of the "practice focus" is not to enumerate individual practices but rather to draw attention to how they function in relation to one another and to a broader scientific enterprise [39]. He describes three key features of practice:

(1) Connectedness: The performances of a practice interact with one another in a meaningful way, and that there is some way to judge the appropriateness of the performance.

(2) Purposefulness: The performance of a practice—and the set of performances-are evaluated and critiqued within a purpose. Within a scientific community, this purpose is its ability to "explain nature." (cf. Ref. [37]).

(3) Prospectiveness: A practice is prospective or forward thinking, which captures how our scientific tools and approaches evolve over time.

Within this paper, we omit the third feature, both for brevity and because we did not have as much evidence of it in our data. Our analysis of the second feature, purposefulness, focuses on whether or not a set of research activities serves a scientific purpose (rather than whether each activity in isolation can serve a scientific purpose).

Within prior research, science has been defined as both a practice and as a set of practices. We find both uses of the word useful. Science as a practice emphasizes the interconnectedness of its constituent activities, and the embeddedness within a community. Some researchers adopt science as a practice to mitigate the possibility that science could become discussed as isolated activities, without sense of purpose $[23,26]$. Others use science as practices to discuss individual practices (e.g., argument construction), with the understanding that each practice is part of a larger ensemble [40,41]. The NGSS explicitly uses the plural science-as-practices approach instead of the singular science as a practice to avoid the idea that science has a uniform set of activities that all scientists engage in [39]. Many researchers flexibly use both meanings of the word practice, depending on the context $[37,42,43]$. Throughout this paper, we use the singular science as a practice $[23,26]$ to emphasize how the features that define a practice (e.g., connectedness and purposefulness) do not depend on the constituent activities. This also aligns with how a communities of practice perspective views practice (in which "activities, tasks, functions, and understandings do not exist in isolation; they are part of broader systems of relations in which they have meaning") [24].

Ford's framework provides a language for us to describe the extent to which a set of scientific activities are scientific practice, based on whether students are able to understand and articulate the connectedness and purposefulness of those activities. Ford frames connectedness and purposefulness as idealized end goals for scientific practice, and challenges researchers and practitioners to think about how one scaffolds early engagement in practice. Taking up this challenge, we apply this framework to a new contextearly UREs - to understand forms of legitimate peripheral participation in scientific practice, and consider how those forms of legitimate peripheral participation emerge through different forms of joint work.

\section{ANALYTICAL APPROACH}

\section{A. Classroom context}

This study is embedded within a larger multiyear study of first-year physics majors' first undergraduate research experiences. Students in the study enrolled in Physics 299B: The Physics Toolbox, a course at the University of Maryland. This course was codeveloped by the first author and another instructor in 2013 and has run yearly since then. In this paper, we focus on data from one focal semester of Physics 299B that was not taught by any of the authors. In this focal year, Quan met regularly with the instructor to brainstorm classroom ideas and talk about how the class was going.

All first-year physics majors who were not currently engaged in research were encouraged to enroll during advising. The course typically enrolls fifteen to twenty students (the physics department typically has about 50-60 first-year freshmen and transfer students per year). In our focal year, five $(31 \%)$ students identified as female and eleven $(69 \%)$ students identified as male. Ten students $(63 \%)$ identified as white or Caucasian, three students (19\%) identified as Asian, two students (13\%) identified as African American, one student (6\%) identified as Hispanic, and one student (6\%) identified as Middle Eastern (students could self-report more than one demographic category).

There are two components to the course: (i) Working in pairs with graduate student and faculty mentors on research projects outside of class and (ii) participating in a weekly seminar, with a separate instructor, where they developed 
research skills and reflected on their experiences. Instructors recruited mentors (faculty, post-docs, and advanced graduate students) who they felt would create meaningful learning opportunities in their research labs. Mentors proposed projects of reasonable complexity for a first-year undergraduate to complete in one semester. Students were matched with mentors based on topical interest. For 3-5 hours per week over twelve weeks, students worked with their mentors on research projects.

Research projects spanned experimental and theoretical physics and astronomy. One focal student in this paper, "Frank," worked on a theoretical plasma physics project with a postdoctoral researcher. Another focal student in this paper, "Neil", worked on an experimental atomic and molecular optics (AMO) project with a graduate student mentor. "Cassandra" worked with a professor on a theoretical cosmology project. Each mentor was given a set of mentor guidelines which outlined the expectations for time commitment, made recommendations for bounding an appropriatesized project within the time constraints, and listed topics covered in the 299B course. Mentors were carefully recruited and were given little feedback over which aspects of physics research to emphasize to students. We did not communicate any of the central themes presented in this paper, such as connectedness and purposefulness, to mentors as potential topics of discussion. Mentors were told that students were expected to work 3-5 hours per week, that the project should be roughly 15 weeks long, and that there was a final paper and poster requirement. Course instructors did not give mentors guidance for how to structure joint work with mentees beyond this basic structure.

In addition to working on research projects, students met for 2 hours per week in the 299B seminar. Course goals and structures were informed by Quan's participation in the Compass Project at the University of California, Berkeley $[44][3,4,45]$. Two central goals guided design of the course: (i) developing a supportive community that shares the ups and downs of doing research, and (ii) giving students opportunities to reflect on and be proud of their work [46]. As a result, much of the seminar consisted of smallgroup and whole-class reflections on students' research activities. The seminar also included open-ended activities for students to learn and reflect on research skills applicable to most research projects, such as reading literature and conducting error analysis. The course culminated in a poster session open to all members of the physics department.

Class discussions did not explicitly discuss connectedness and purposefulness. However, it is likely that class activities supported students in seeing scientific activities as connected and purposeful. For example, one course activity involved constructing an "elevator pitch," or a short verbal summary of one's research for someone not in one's field of study. Students also drafted and gave each other feedback on their scientific posters. In both of these activities, students were told to articulate the main point of their work, which likely encouraged them to consider the flow of activities and how they supported a scientific purpose. We acknowledge that Quan's involvement in co-designing the course could impact our interpretations of the data; however, the focus of this paper is on what happened in the outside research groups, which was minimally structured by the course design.

\section{B. Data collection}

The purpose of this data collection was to understand how students shifted participation within a physics community of practice. When we began data collection, connectedness and purposefulness had not emerged yet as themes for analysis. In the focal semester, Quan collected classroom videotapes, observations of students in their labs, and interviews with students and mentors. Because our analysis was focused on identifying shifts over time, we conducted pre- and postinterviews. All preinterviews were collected before students had started research projects, except for Cassandra's interview, which was conducted four weeks into the research projects. Because we expected to identify participation via how students were positioned by others or positioned themselves as more or less expertlike, we also interviewed mentors and observed research lab interactions.

All 17 students were invited to participate in classroom data collection and pre- or postinterviews. We collected six preinterviews and eight postinterviews (five students participated in both). Interviews were semistructured [47] and topics included students' attitudes toward their research project, students' sense of belonging within the physics major, and what they felt like they were getting out of doing research. In postinterviews, the interviewer also followed up with students on themes discussed in the first interview.

For the six students who completed preinterviews, we invited all five of their mentors to participate in interviews midsemester. Four mentors participated. Mentor interview questions asked them to describe their research projects, how they thought students were doing in the project, and what their goals were. After collecting mentor interviews, Quan invited the four mentors who had been interviewed and their mentees in those groups to participate in research observations. Quan conducted three research observations. Three focal students participated in interviews one year after the course ended. We elaborate on the selection of these case studies at the end of this section.

Our data collection and analysis drew from ethnographic approaches in three ways. (i) Ethnographies conduct in situ observations of participants in their natural environments [48]. In this work, we observed students in the 299B classroom, and (when possible) in research activities. (ii) Ethnographies also rely on interviews with members of the focal community in order to understand the community itself $[31,49]$. These interviews complement observations by providing insight to what an individual's 
experience is within the community, how participants perceive the goals and activities of the community, and what the common sense knowledge is within the community. (iii) Ethnographic methods tend to study participants over extended amounts of time (months or years) to build shared meaning between participants and ethnographers. Members of communities have shared language and nuanced ways of understanding words and phrases that may feel unfamiliar to outsiders in the community. We conducted our research over several months to build shared understanding with research participants [49].

\section{Case selection}

In this paper, we present analyses of three focal students: Frank, Neil, and Cassandra (summarized in Table I). We chose these students because they had high, mixed, and low senses of connectedness and purposefulness of their projects, respectively, and we wanted to understand these differences. In the cases of Frank and Neil, we also had data from the student's lab partner and mentor. In the case of Cassandra, we did not have data from either the mentor or partner. Interview data from Cassandra's mentor and partner would have helped us triangulate our claims about the form and structure of her research experience; however, even if her mentor had intended to support connectedness and purposefulness, we still privilege Cassandra's accounts of whether she saw them as connected and purposeful. We still choose to include Cassandra in this paper because she described the most limited connectedness and purposefulness of any student in the data set, and because her interview data were sufficient to characterize her sense of connectedness and purposefulness.

There were two additional projects for which we also had mentor interviews. In one group, which was an observational astronomy project, poor weather meant that the group canceled most of their meetings, so students met infrequently with their mentors and their participation in physics practice was limited. Though this group had a more "complete" data set, we chose not to include it in this paper because the group spent little time doing research, making it challenging to characterize what forms of joint work they engaged in. The other group was similar to Frank's; the students regularly worked alongside mentors in lab and they were able to articulate the purposefulness and connectedness of their activities.

Because of limited space, we choose to present focal students only. Our purpose is not to reach broad generalizations about how features of joint work affect students' engagement in scientific activities. This is an exploratory study, intended to (i) make plausible our claim that features of joint work affect students' engagement in scientific activities, and (ii) illustrate mechanisms by which these may be connected. We hope this study motivates future qualitative work further charting these mechanisms and quantitative work exploring these connections more systematically.

\section{Analysis}

After the first round of preinterviews was collected, Quan developed content logs [50], which noted the main themes of each interview. We were initially interested in how students did or did not have access to physics activities, so we flagged moments in which students and mentors positioned students relative to the activities of the discipline. Throughout this process, several themes emerged such as how activities were contextualized within what was valued by the physics research community, and the ways in which students were invited to participate in physics activities. During this process, we moved between our emergent categories and themes in the literature, including students' senses of connectedness and purposefulness of the set of activities in which they were engaging. After refining categories, we fully transcribed the interviews and flagged moments in which students or mentors described their lab-related activities as being connected (or not) to one another or purposeful (or not). We labeled sets of activities that were connected and purposeful as practice.

We then developed analytic memos in which we used transcript segments to develop claims about how features of the project and working relationships supported connectedness and purposefulness [50,51]. We refined our analyses by synthesizing our accounts of students and mentors on the same mentor-mentee research teams [52,53]. In all cases, students and mentors gave well-aligned descriptions of central features of the project and of their working relationship. Interpretations of interview data were interrogated by a researcher who was closely involved with (Quan) and researchers who were distant from (Turpen and Elby) the research setting.

Ford's paper is theoretical and describes features of a scientific practice in an idealized form instead of what it looks like for students engage in that practice. Therefore, we had to link Ford's features to what can be inferred from interview data. As researchers, we believe our interpretations of students' engagement in connectedness and purposefulness using interview data is one facet of their engagement in scientific practice. Analyses drawing on in situ data would illuminate complementary facets worth exploring [53].

We inferred connectedness when students described several activities as following one another sequentially, when the latter activities plausibly built on the earlier ones (e.g., "we learned theory of circuits, then we played with circuit parts"). Stronger evidence involved students more explicitly describing one activity as being contingent on or building from one another (e.g., "we implemented code based on the theory we had learned before"). We identified purposefulness in statements in which students described how the set of research activities generated knowledge within the physics research community. This included instances when a student framed their work in terms of a question unanswered by the physics research community 
or articulated what scientific knowledge was gained from their work. In some instances, students articulated that they did not know how their work would benefit the scientific community, which we took as evidence of lack of purposefulness. We also noted instances in which students found their work personally meaningful or purposeful toward other goals-e.g., a student saying his project was meaningful because he enjoys feeling like he helps others-but we chose not to include those in this paper because this is a different sense of purposefulness than the one in Ford's framework.

We take these descriptions of the connectedness and purposefulness physics activities as evidence of students' participation in physics practice. We consider more complete descriptions of connectedness and purposefulness to be evidence of deeper participation in physics practice. Consistent with a LPP approach, we define deepening of participation in the practice as learning. Within this paper, we do not use data to show that shifts in participation happened. Preinterviews with Neil and Frank occurred after students had ranked their interest in projects, but had not yet begun research. In both interviews, Neil and Frank described surface features of their projects, but had very minimal senses of connectedness and purposefulness. We interpret any description of connectedness and purposefulness in post-interviews to be evidence that they shifted participation in practice, and consequently were learning. While we would benefit from also having a preinterview from Cassandra, it is not necessary for our claims that she had a low sense of connectedness and purposefulness.

Our theoretical perspective and early analyses informed which aspects of joint work we chose to focus on. As noted above, Lave and Wenger suggest that shared activities and relationships between members impact engagement in the activities of a community of practice [24]. In trying to understand mechanisms driving connectedness and purposefulness, we similarly noticed that students described several aspects of working relationships and interpersonal dynamics as being consequential. We then developed analytical memos noting how these aspects seemed to impact students' engagement in activities. Using Spradley's approach to ethnographic analysis, we constructed categories of joint work that came up as relevant (e.g., "responsiveness to concerns" and "flow of activities.") [54,55]. We then looked for and studied each of these categories within the broader set of data. Incorporating more data, including mentor interviews, helped us expand and collapse categories, and then we repeated our analysis. By iteratively refining our categories and looking across more data [52], we identified two main grain sizes of joint work to focus on, project form and structure, and patterns of interaction. Throughout this process, some features of joint work stood out as salient only once they could be seen in relief of the broader data set. For example, a student describing a research mentor as "always available" became more meaningful when another student described interactions with a different mentor as "sparse." These analyses and video data were also presented at research group meetings to identify the claims that were best supported by the data [50].

Our work aims for what Eisenhart [56] calls "theoretical generalizability." Rather than building claims about the representativeness of a population of students, we develop theoretical inferences that can be extended and refined in other cases. These theoretical inferences make claims about deeper theoretical phenomena that underlie each case, though how they play out may look different in each case. We similarly align our work with what Robertson, Scherr, and McKagan call "case-based" PER, which aims to use cases to develop and refine theories, and can illustrate mechanisms by which certain phenomena occur [57]. This differs from "recurrence-oriented" PER, which instead aims to develop claims about the reproducibility and recurrence of phenomena.

Our cases were chosen to illustrate how the relationship between joint work and participation in physics practice looks different across three cases. We tested and refined the robustness of our claim by checking if it held up in all of our data. These cases also add explanatory power beyond what has been explored in the literature. We differ from prior work on UREs by looking at engagement in practice (as defined by connectedness and purposefulness) instead of isolated skills and activities (cf. Refs. [7,8,13]). We also attend to the structural nature of mentor and mentee relationships (patterns of interaction and joint work) as opposed to personality traits and frequency of meetings (cf. Refs. [7,13,16,19-21].

In the next section, we discuss the affordances and drawbacks of relying on interview data to discuss engagement in activities and patterns of interaction in labs.

\section{Using interviews to infer patterns of interaction and students' engagement}

Historically, interviews have been used to infer students' perceptions and abilities whereas observations and video analysis are more commonly used to study engagement. Within our analyses, we use interview data to make claims about engagement outside the interview setting, drawing on literature and constructs that were primarily developed using in situ data collection.

We identified students' senses of engagement in interview questions prompting students to describe what it was like to do research in their labs, such as "Can you tell me about your research in 299B?" "What was your relationship with your research mentor(s) like?" and "What would a typical day in research have looked like?" These questions give us access to aspects of what students are doing and thinking that may not have been verbalized within mentor-mentee interactions. We also gain access to features of interactions that are most salient to participants; because 
our ultimate goal is to understand students' long-term participation in physics, we find their "truth" about these interactions to be especially relevant.

Interviews also give insight into the flow of activities without watching them the whole time within the research experience. Given the time required to collect and analyze observational data, it may not be feasible to develop analyses about the flow of activities in several research groups through observation [58]. Finally, the aspects of interaction that we choose to foreground here, descriptions of joint work including which actors are present and those actors' roles within joint activities, is more likely to be reliably reported compared to accounts of the fine-grained details of a conversation. The alignment of students' and mentors' depictions of joint work and the roles taken on by each person in the group gives us further confidence that those depictions capture aspects of lab interactions.

Had we been more interested in students' performancebased skills or effectiveness at doing research, conducting interaction analysis on in situ data would be a better approach. We emphasize, however, that although we might have intuitions that video recordings might have more objective views into patterns of interactions, this viewpoint can harmfully obscure researchers' subjectivity and theoretical commitments $[59,60]$.

We used other data sources to strengthen our analyses. Quan attended and videotaped every meeting of the 299B seminar, which provided space for students to share detailed descriptions of research experiences and problem solve about their projects. Quan also conducted one research-lab observation of Neil, his partner, and his mentor, and one research-lab observation of Frank's partner and mentor (with Frank absent that day). In both classroom and research settings, Quan was not a passive observer; she asked clarifying questions, contributed to discussions occasionally, and informally talked with students about their academic and personal lives. These observations contributed to greater shared meaning during the interview conversation and our interpretations of students' descriptions [49]. When available, we analyzed research mentor interviews, and interviews with research partners (in the same research group) to triangulate these accounts.

An important next step to this work would be to analyze in situ research observations to better articulate joint work and understand how connectedness and purposefulness is supported in moment-to-moment interactions. Our interview-based analyses in this paper give insight to where one might focus attention in such analyses.

\section{Moving between grain sizes of participation in disciplinary communities}

Wenger [25] and Brown and Campione [61] motivate us to look at participation in disciplinary communities at both broad and narrow grain sizes. We consider the broad grain size to be project form and structure, the larger scope of an investigation and flow of activities, whereas patterns of interaction happen at the day-to-day timescale.

Wenger describes the activities of medical claims processors at both the broad project form and structure level and the narrow patterns-of-interaction level [25]. At the project form and structure level, the arc of a processor's role is to receive claims, process them in spreadsheets given by the company, and check their work. At the finer-grained level, several patterns of interaction support this broader structure. New members rely on old timers for feedback in developing a "feel" for appropriate spreadsheet outputs. Discussions with and observations of old timers also help enculturate new members into norms regarding day-to-day activities such as phone calls and birthday celebrations. In Wenger's description, both of these grain sizes of activities impact and reflect claims processors' roles in the community.

In a different vein, Brown and Campione describe their Fostering Communities of Learners classroom as a broad system where reflection and disciplinary content support research, information sharing, and engagement in a consequential task [61]. At a smaller grain size, they also describe regular patterns of interaction that support this system, such as distributing expertise across group members and conversational norms around epistemic engagement (e.g., providing warrants and backings for scientific claims).

Within our work, we consider these two grain sizes of joint work that emerged as consequential for how students engaged in disciplinary activities. These two grain sizes first emerged empirically, but we found that they matched up to similar grain sizes that other researchers had used.

Project form and structure.-This grain size focuses on what the driving questions are, the scope of the investigation, and the overall flow of the joint activity. Driving questions are the broader goals of the project and how the project fits into the disciplinary domain. The scope of the investigation includes the boundaries of what is and is not being researched. The overall flow refers to the sequencing of activities, and the logic behind that sequencing. Underlying the flow is the epistemic approach to the project, or how the project has the potential to produce disciplinary knowledge. An example of an epistemic approach would be that an experimental observation should be theoretically verifiable, which justifies why one should look for theoretical models that explain anomalous experimental observations. This structure is negotiated between members of the community and scaffolded by more expertlike members to varying degrees.

Patterns of interaction.- This includes the more day-today interactions that occur in research, such as orientation to tasks, spatial arrangement of actors and materials, timing of interactions, and how accessible actors are to one another. We draw on Barron's characterizations of group work to describe patterns of interaction [33,34]. For example, a co-working relationship might involve students 
and mentors maintaining joint attention on the same task. Another pattern of interaction involves mentors and students working on different tasks in the same space, with the student asking frequent questions. Similar to Erickson's social participation structure [62], this includes how people act in the setting and who has information. Within patterns of interaction, we were especially attentive to responsiveness, noting the manner in which and timescale over which the mentor responded to mentee's concerns, and the processes by which mentees asked questions and received feedback.

Markers for joint work were mentor or student statements that described aspects of the working patterns and relationships between students and mentors. We specifically focused on descriptions of project form and structure (the sequence of activities, division of labor) and patterns of interaction (interactional dynamics such as physical arrangements, spontaneity of interactions, and responsiveness). In other analyses, we attended to more interpersonal qualities of relationship building such as senses of belonging and friendship building. Because of limited space, we

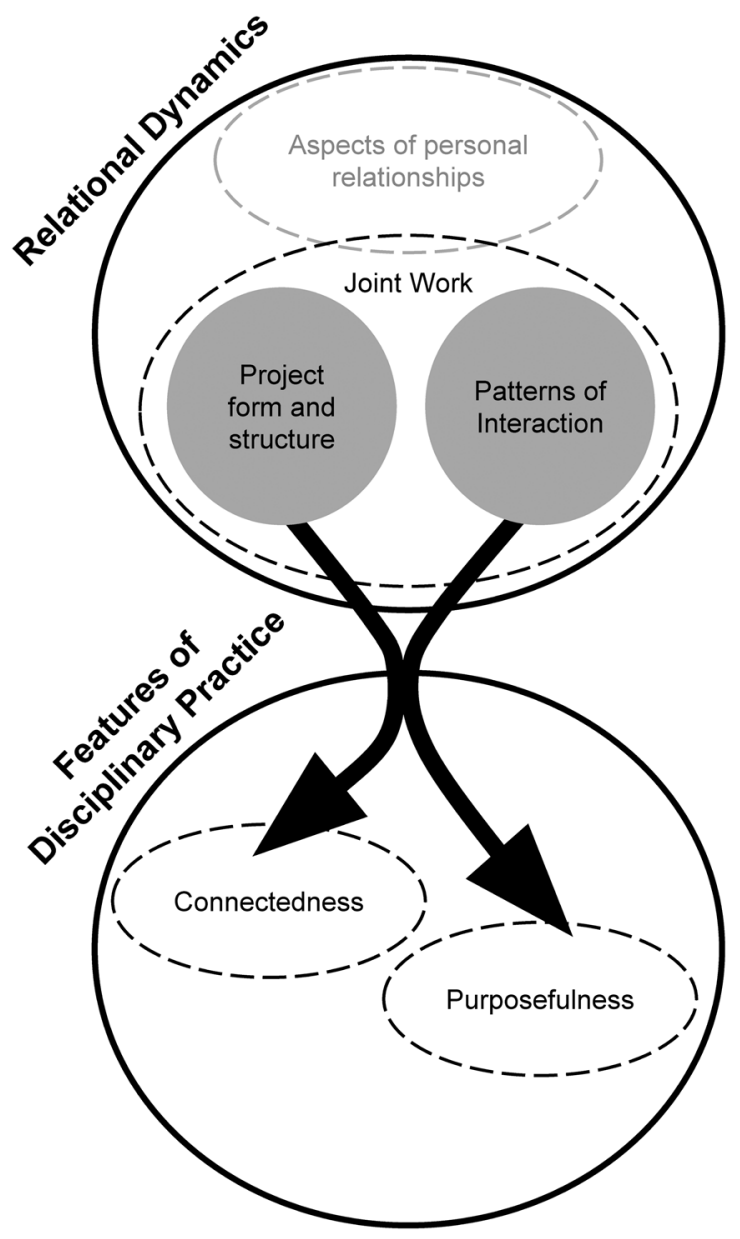

FIG. 1. Analytical framework in this paper. Project form and structure and patterns of interaction both connect to connectedness and purposefulness. will discuss these aspects in future work. Figure 1 illustrates the connections between joint work and disciplinary practice that we identified in this paper.

To summarize, our study of legitimate peripheral participation in the physics community of practice focuses on two aspects of participation: engagement in physics practice and the joint work that students and mentors engage in. To study physics practice we use a framework from Ford in which a scientific practice is defined by the connectedness and purposefulness of its constituent activities. To study joint work, we focus on the broad project form and structure and the patterns of interaction between mentors and mentees. In our analyses, we look for ways in which the joint work affects students' engagement in connected and/or purposeful scientific activities (Fig. 1).

\section{RESULTS}

For each of the three cases, we first provide a descriptive account of their joint work at two grain sizes: project form and structure, and patterns of interaction. Next, we describe the connectedness and purposefulness of the disciplinary activities in which they engaged. Finally, we illustrate how the forms of joint work impacted the degree and nature of the connectedness and purposefulness.

\section{FRANK}

Joint work between Frank, his mentor, and his partner consisted of Frank's mentor setting clear learning objectives each week and letting students work on their own or participating in mentor-guided work together. They also engaged in regular periods of joint attention and shared task alignment, while engaging in critique and evaluation of their work. We argue that having well-articulated objectives and opportunities to co-work supported Frank in understanding the connectedness and purposefulness of their activities.

\section{A. Descriptive accounts of joint work}

Frank worked on a computational physics project modeling plasma in the ionosphere. Other researchers had detected radiation in the South Pole and suspected that it had been the same radiation that had been transmitted into the ionosphere in the North Pole. Using ray tracing in the computer modeling language MATLAB, this project modeled whether it was physically possible for the radiation in the North Pole to scatter through the ionosphere all the way to the South Pole.

\section{Project form and structure: A step-by-step approach}

Quan interviewed Frank's mentor halfway through the research project. He described planning out the project "from the ground up" and taking a "step-by-step" approach. 
Interviewer: So are there other things are you hoping that students will get out of this experience?

Frank's mentor: ...There are multiple sources that I could have given them, and I could have told them how to do it on MATLAB, and I could have just let them do it...Just kind of like, "hey here's the equations, just turn the crank on the computer." That's not the approach I took...I went step by step, I said "you know, if you want to do this you have to know how to program in MATLAB, how to use MATLAB as a computational tool."...We learned the basics of MATLAB... then actually solving ODEs [ordinary differential equations] on the computer... Then we moved on to theoretical foundations of the equations... at least some background where they come from... to, "hey like, guys, this, what you just learned leads to these equations," ... we'll go back to MATLAB then and we solve the equations on the computer. And that's really when more of the research questions are going to be asked. That's when you're like, okay, so what research questions am I asking? And what am I looking for when I'm using the computer? And solving these equations and what output, what do I want to see in my output and finally, what is the output? What are the results? And then that's the progression.

Frank's mentor first describes an alternative mentorship strategy where the mentor tells students how to solve a problem and lets them "turn the crank." He explicitly rejects this approach, in favor of an approach "from the ground up." This approach goes step by step, starting with learning the basics of MATLAB, then theory, and finally integrating those to answer a research question. In the mentor's interview, he articulates those steps and how they build off of one another. These start from the ground up, beginning with "basics of MATLAB" and "foundations of the equations" before solving the equations in MATLAB. He connects these solutions to the research questions that drive their work. Frank described a similar flow of activities, which we show in the next section.

\section{Patterns of interaction}

Frank, his partner, and his mentor met twice per week. When asked to describe a "typical day in research," Frank described several interaction patterns of him, his mentor, and his partner.

Interviewer: What would a typical day in research have looked like for you guys?

Frank: [Mentor] would explain to us what the objective was for the day. Whether it was basic coding towards the beginning of the sessions or theory of the plasma frequency and the index of refraction. He lays down the groundwork, and then we go in. We start coding exactly what we think should happen... from what we know, and then submit that to [Mentor], he would look it over, and then we confer... Or it would be [Mentor] gives us a code and tells us to play around with it and see what we can do... [My partner] and I then figure out whether our ideas are aligned, whether they're not aligned, what makes sense, what doesn't make sense. And so it would be a group project, where we go back and forth. We all have a third of the project to do. And, we confer and we make it a whole.

Frank stated that his mentor explained their work in terms of daily objectives, suggesting that his mentor supported them in breaking their work down into smaller subgoals. This division into daily objectives aligns with the step by step scaffolding as his mentor described above. We interpret Frank's description of going "back and forth" between doing one's part of the project and conferring to "make it a whole" to mean that their work oscillated between working separately and co-coordinated activities.

Frank describes several places where they maintained shared task alignment and joint attention, "he lays down the groundwork," "we confer," and regular evaluation of his work with his partner and his mentor. Throughout the interview, Frank consistently used the word "we" or "and I" when discussing research activities. Frank's description aligned with the working patterns that were observed in our observation of their research team, in which Frank's mentor observed and guided his partner through derivations of differential equations on a whiteboard. According to Frank's mentor, they met for two one-hour meetings per week in a conference room that he had reserved. Frank's mentor described the bulk of their research activities as being done within these in-person meetings, stating "Right now we're going from theoretical foundations to equations... after one or two meetings we're going to immediately move onto the full problem and it will take another meeting or two after that to finish." We interpret Frank's mentor's use of we and his account of accomplishing subgoals within meetings to mean that activities were co-coordinated. These accounts of doing work together in the same space aligns with Frank's and Frank's partner's accounts of how work was done.

\section{B. Engagement in disciplinary activities}

Frank's mentor described the scientific activities in terms of how they connected to one another and answered a scientific question. In the above quote from Frank's mentor, he noted many of the activities and how they are connected to one another in a step-by-step way. First, students learn how to solve ordinary differential equations in MATLAB. Then they learn "theoretical foundations" so they know where the ODEs they would program came from. Finally, they integrate this theory and programming into solving equations for their system on the computer. At this point, the activities come together toward answering, "What research questions am I asking?" 
We found evidence that Frank also experienced connectedness and purposefulness with respect to scientific activities.

\section{Engagement in connected activities}

In the above quote from Frank, he drew connections between computational and theoretical aspects of his research, as well as how their engagement connected to scientific critique. Within this description, there is evidence that activities are connected for Frank. He outlines several activities such as "laying down the groundwork," enacting computation, and engaging in evaluation of those performances. Frank's use of the transitions "and then" between the activities suggests that they are connected sequentially. Embedded within Frank's statement is also how he sees each activity directly informing the next. The coding processes directly connect to their conceptual knowledge ("we start coding exactly what we think should happen... from what we know") suggesting that the computational processes were contingent on conceptualizing predictions of what they thought would happen and "groundwork" that had been developed before. In the second half of the quote, Frank describes another mode of engagement in which they explore a code that had been previously developed by other researchers. Using this exploration of previously developed code, they figure out "whether our ideas are aligned" with one another's. This critique is connected to the understanding they developed through previous exploration of the code. This is consistent with Ford's definition of practice, in which the connectedness of activities is evaluated and critiqued [26]. Frank's description of how scientific activities flow into one another makes sense to us as researchers and helps us understand how Frank is making sense of the logic behind his inquiry.

\section{Engagement in purposeful activities}

Frank also described the scientific purpose of the set of research activities and how the purpose emerged from prior research:

Interviewer: So can you tell me a little bit about the research you did in 299B?

Frank: Well basically we built a theoretical model of what was already done by researchers in the North Pole... nobody has ever actually traced the path or given a concrete, a concrete statement saying that "oh this is definitely possible"... We just made a model of what potentially was what made it to the South Pole.

Frank situates his research in terms of prior research and what is unknown. They used representational tools (ray tracing in a waveguide) to develop a computational model which would answer a question, whether radiation in the northern ionosphere could scatter to the South Pole. Frank's description not only states that their research is purposeful because it answers an unknown question, but also presents a coherent account of how each of these steps connect in order to achieve a scientific purpose. This is aligned with Ford's description of scientific practice, in which the set of activities make sense in terms of a scientific purpose.

\section{Linking joint work to engagement in disciplinary activities}

We argue that the structure of Frank's research experience supported him in seeing activities as purposeful and connected, thus we see them as physics practice. The step-bystep nature, daily objective setting, and regular opportunities to work together on joint activities supported the connectedness of Frank's research experiences. Frank's mentor had intentionally taken a step-by-step approach, setting a broad project workflow that involved theory and coding. In describing this approach, Frank's mentor emphasized the importance of how each of these steps built off of one another. Frank similarly described how coding was based on their theoretical understanding. The mentor's intentionality in planning out several connected steps likely led each of the activities to meaningfully build off of one another. Frank's research team also did a significant amount of co-coordinated working on joint research activities. Within these activities, his mentor was responsible for identifying each step in the process, laying down groundwork, and giving feedback. Their regular activities included having the mentor critique students' work as well as Frank critique his work with his partner. Frank describes this evaluation as checking how well their code aligns with one another's, what they know, and what makes sense. We interpret this to mean that they compared their computational models to the conceptual understanding that had influenced their coding, directly connecting theory and computation together through evaluation. Frank's mentor also discussed how these interconnected activities are intended to support them in asking and answering a research question, which likely supported Frank in seeing the purposefulness of his activity.

\section{NEIL}

Neil described the scope of his project as narrow; he developed a device to understand if temperature fluctuations in his lab were impacting the lab's major experiment. In doing this project, Neil, his partner, and his mentor worked fairly close together, with the mentor often being in a nearby room. We argue that these working patterns, along with his mentor's intentional setting of the project structure contributed to a smooth workflow that resulted in Neil seeing scientific activities as connected. We also argue that the narrow scope of the project contributed to his limited sense of purposefulness.

\section{A. Descriptive accounts of joint work}

Though Neil worked in a lab studying Bose-Einstein condensates (BECs), the project was mainly motivated by a 
unique challenge faced by the lab; Neil and his partner designed a device to determine if temperature fluctuations in the lab were impacting the lab's major experiment. Neil's mentor had the students design a circuit to measure temperature, create a printed circuit board (PCB) of their designed circuit, use the circuits to collect temperature data, and analyze whether fluctuations in temperature matched fluctuations in the lab's experimental data.

\section{Project form and structure}

Neil's mentor described the structure of Neil's project as "make some widget, use widget." In his description, he emphasized the value of the widget design and measurement connecting to one another:

Interviewer: So what are you hoping that students get out of this research project?

Neil's mentor: The whole encompassing thing of course is to take things that have been designed and worked out or whatever and actually make a measurement, or something, or do something, get a good result using what they have done... [The] structure, of all the projects is make some widget, use widget to measure something we didn't know and, I feel like both are equally important experiences to have, in combination... That whole combined package of that is really what I want out of these projects for them...and have the experience to see through the arc of a smaller project.

Neil's mentor refers to all his URE projects as make some widget, use widget. In this quote, he emphasizes the connectedness of designing a "widget," building it, and using it to conduct an investigation. He uses the phrases "whole combined package" and "arc of a smaller project," which suggests that he sees the project as a contained unit relative to the broader research lab. The idea that the project is a smaller unit comes out on Neil's description; he calls the project "a specific little task."

Interviewer: Was there anything you feel like you gained from that experience?

Neil: We had a specific little task we had to do. Um, and it didn't actually require us to understand fully the uh, physics behind what the lab was working with. We just had to understand our little tiny part, and so uh, we just applied what we know about electronics and circuits to that part and we made our sensor. And so that's sort of how it is overall. You don't have to understand everything about it, you just have to understand a small enough portion to um, complete whatever the lab needs done...

Neil states that the bounded nature of the project meant that he did not have to understand the broader physics behind the lab's main experiment. He states "we just had to understand our tiny part."

\section{Patterns of interaction}

In addition to thinking through the broad scope of the project, Neil's mentor emphasized the importance of anticipating next steps and being available to answer questions. He stated, "There's gotta be a trail. You gotta plot this out, or whatever, beforehand, and know what's coming up, to be able to help them out," valuing knowing what is ahead, and anticipating roadblocks that students would encounter.

When Neil's mentor stated that his role was to plot out a trail, he did not see this as prescribing everything that they were supposed to do. He later described a balance between giving students some freedom but not being totally lost.

Interviewer: So in terms of helping students experience something not working, are there ways you try to help them deal with that?

Neil's Mentor: it's always hard to, like, balance because you want to give the freedom to explore and learn on own... to have some, difficulties, and overcome them and learn... I give them a little bit of room to figure out what's going wrong first... if they sincerely have tried, then that's when I want them to come to me and we can talk about it.

At the end of this quote, Neil's mentor states that he wants students to come to him with questions if they can't figure something out. In Neil's interview, there was evidence that Neil also saw his mentor as available to answer questions.

Interviewer: What was your relationship with your research mentor like?

Neil: It was good, I mean, any question we had, he was very helpful. Imean, he showed us, taught us, about all the different circuit things we need to know that we probably didn't know to begin with, like operational amplifiers and that sort of thing. And yeah any questions we had he was there, uh, so yeah I would say it was good.

Neil states at the beginning and end of this quote that his mentor was available to answer questions. He also notes that one of the things that made his mentor helpful was that he "taught us about all the different circuit things... that we probably didn't know to begin with." This aligns with his mentor's statement about anticipating the kinds of things that Neil and his partner would need to know.

One important feature of their team's workflow was that Neil also was in close proximity to his mentor and partner, which offered more spontaneous moments of joint attention. The three of them met twice per week. His mentor was often nearby, even when they were working on separate projects. Neil described their workflow:

Interviewer: I'm wondering about the day to day work in the lab. What role was [your mentor] playing? 
Neil: At the beginning he went over and told us all the uh, all the circuit theory we didn't know and uh we'd go off, we'd leave him in his office, and we'd go off into the electronics room and start playing with components, and trying to get them to work and uh, seeing how, you know, putting the theory to actual application. And we'd do that for awhile, and [our mentor] would come in and check on us, and uh, if we had any questions we'd ask him then. And if we, during all this, if we had any-if nothing worked like, "oh my god," we could just go and grab him, like, "something's wrong!" He'd help us, then later...we ended up making a printed circuit board so we had to, uh, take our little breadboard and design on a computer into a PCB, and uh, when it got to that, he showed us how to use the [software for printing PCBs] program for doing that, and then, he just left us to do it while he went about and did his lab work and stuff and again he'd just come in every once in awhile and just ask questions, that sort of thing.

Neil describes how his partner and he would separate from their mentor to work on their own, but that their mentor would regularly come to check on them and "just ask questions," maintaining involvement in what they were doing. If they ran into roadblocks, they could go to him wherever he was working and get help. Throughout this quote, there is a sense of close spatial proximity between Neil and his mentor that allows them to fluidly move in and out of shared task alignment and joint attention. There is also the sense that Neil's mentor was seen as available to be interrupted when doing his own work, so that he could respond to students' concerns as they came up.

\section{B. Engagement in disciplinary activities}

\section{Engagement in connected activities}

In the above quote from Neil, he describes several scientific activities in connected ways. He states that they started by learning circuit theory. Afterward, they engaged in circuit building in the electronics room, which he describes as "putting the theory to actual application." This suggests that he saw the circuit building as directly connected to the theory they had learned before. After they had come up with circuit designs, "we had to uh take our little breadboard and design on a computer into a PCB..." The practice of designing a PCB on the computer directly connected to the breadboard circuit they had built before.

Earlier in the interview, Neil gave an overview of their project.

Interviewer: Could you just like reflect a little bit on the research you did in 299B?

Neil: We were working in a lab that dealt with uh BoseEinstein condensates, and uh, they would calculate magnetic field of these condensates. And it would be based off of some complicated formula but that relied on the amount of current that one of their sensors output. And uh, what they had saw was that there was fluctuations in the current and they weren't sure why. They thought it might have been temperature and so uh, me and my partner we, uh, designed a circuit to uh, measure temperature and then we get the data for it to see if there's a correlation between the temperature and the uh, the changes in the current. And it turned out there-there seemed to be and even by manipulating it a little bit by uh, putting like uh, well like a hot air gun against thermostat to cause a temperature to be colder [the thermostat detected the hot air, which led the room to cool itself] and stuff like that, you could actually see spikes...

Neil first described prior work that the lab had done that motivated this project. The circuit design directly stemmed from the research group's hunch that temperature fluctuations might be causing current fluctuations. This suggests that he saw his circuit design as connected to prior work. He then articulates several activities-designing a circuit, collecting data using the circuit, and analyzing the datain a steady stream of talk using conjunctions "and" and "then." The continuity in his speech also suggests that these activities were connected to him.

\section{Engagement in purposeful activities}

While Neil engaged in connected scientific activities, we argue that his engagement in scientific activities was less purposeful. In Neil's interview, he was able to describe why the activities he engaged in were relevant to the lab's experiment, but not how the experiment itself fit into a broader scientific research purpose.

Interviewer: Alright, how much did you feel like you understood how your research fit into the broader goals of the lab?

Neil: Um, well, I'd say not very well. I mean I understood that they're trying to clean up some data and remove some weird fluctuations but why they're measuring the uh the electric fields of the Bose-Einstein condensates, that sort of stuff I didn't really understand.

Neil experiences the activities as being purposeful, but his participation is peripheral; he describes that the widget helps the lab "clean up some data." He is also able to articulate the prior observations and data fluctuations in the lab that motivated the project, as shown in the previous section. On the other hand, the broad importance of that data is opaque to him, and he notes that. While he is able to participate peripherally in some activities of the lab by understanding how his project helps the experiment, he has not fully engaged in physics practice because he does not understand the broader purpose of the enterprise.

The example of Neil suggests that there are at least two aspects of the "purposefulness" of scientific activities. 
One is seeing how one's activity can contribute to a particular experiment or research group. The other involves understanding the scientific "point" of the experiment and why (in this case) removing current fluctuations would help. Peripheral participation in purposeful activities, as illustrated by Neil, can involve believing that BECs are scientifically important and that his work is contributing to understanding them better.

\section{Linking joint work to engagement in disciplinary activities}

The form of Neil's legitimate peripheral participation was characterized by his mentor giving Neil a small contained project that they worked closely on. We argue that this contained structure impacted Neil's limited sense of purposefulness. Patterns of interaction and project form and structure supported Neil's sense of connectedness. Because he described activities as connected, and only somewhat purposeful, we argue that Neil's experience was somewhat aligned with Ford's description of practice.

Neil's mentor structured their activities by plotting out a trajectory and anticipating challenges. Neil described their workflow as involving regular informal checking in from his mentor, and his mentor being available and nearby while Neil was working. We argue that working in close proximity as well as his mentor's responsiveness contributed to a smooth workflow between them where roadblocks could be addressed quickly and Neil's mentor maintained engagement in what Neil was doing. We argue that this smooth workflow likely led to increased opportunities to see the connectedness of their activity.

The structure of Neil's research project, building and testing a device, was mainly motivated by a challenge faced in Neil's specific lab, instead of a broader research question in the scientific community. An understanding of the broader scientific purpose of the lab's activities were not necessary to completing this specific task either. We argue that this contributed to Neil only engaging in the local purpose, without engaging in the broader purpose.

Neil's experience demonstrates that legitimate peripheral participation in physics practice can involve understanding narrow aspects of the scientific purpose-how it contributes to a given experiment— but not fully understanding the broader scientific purpose. This bounded purposefulness can emerge from having students work on a small project where having a broader understanding of the lab's research is not necessary. This contrasts with Frank's experience, where Frank was able to articulate how his research contributed to broader scientific understanding.

\section{CASSANDRA}

Cassandra worked with a research scientist on a project creating visualizations of simulations of the early universe. Cassandra described interacting sparsely with her mentor, with most of their work done asynchronously. We argue that this contributed to Cassandra's limited understanding of the purposefulness and connectedness of the visualizations.

\section{A. Descriptive accounts of joint work}

\section{Project form and structure}

In the postinterview, Cassandra describes her project as creating visualizations of simulated data. The flow of their activities was to learn to use the visualization tools, then to create visualizations of their mentor's data.

Interviewer: Can you tell me a little bit about the research you did in 299B?

Cassandra: ...We were just taking, um, data from our mentor which was, um, theoretical data that he had... He uses this code to generate this data which like, simulates the early, early universe... We visualized his data basically and then just-we weren't able to draw conclusions from it... we did find a possible bug. And I think that, taking it further we would have examined like um, more visualizations to look and see if the bug is real or if this is something else, and then looking at the code directly and trying to figure out like how to fix it or what was wrong... I feel like it was more like a computer learning thing. I can see how that is a part of research. You know, like a part of research is to look at data and visualize it but I think we only did a small piece of something.

From Cassandra's description, we see that she was working with data from a simulation that her mentor had created. Her role was to visualize the data through learning and using a visualization package in PYTHON. Cassandra later stated that her mentor did not know how to use this package, so Cassandra and her partner were primarily learning from online resources.

Since we do not have mentor data from Cassandra, we do not know if there were implicit driving questions or learning goals. If there were, Cassandra does not seem aware of them. Moreover, Cassandra does not describe a clearly laid out epistemic approach, or sense of how this project could have produced some kind of disciplinary knowledge.

\section{Patterns of interaction}

Cassandra did most of her research at home on her computer or with her partner, with occasional meetings with her mentor. In Cassandra's postinterview, she described feeling like she was not getting the amount of time that she wanted, stating "You know like I did have to push a little to get to work with him..." She goes on to describe their relationship as "scarce." 
Interviewer: So how was- what was your relationship like, with your mentor?

Cassandra: Umm, scarce...he was a busy person and preferred email exchanges. But I kinda forced him to see me anyways. Cause I don't know I just felt email exchanges were impersonal, and I didn't-if I had questions, you know on the fly, you can't really do that through email. But we-we didn't see him often, like maybe every other week. But we didn't really need him either, so I think like he was easy to get information from, like he wasn't a jerk or anything, but he was kind of an introvert. So you know, I had to work around that.

Cassandra positions the mentor as preferring email or online communication instead of meeting in person. She attributes him preferring online communications to being an introvert and being busy, which she had to accommodate. This gives Cassandra little opportunity for shared task alignment and joint attention. Though Cassandra's mentor does not seem to seek out meetings with her, she does describe how she took an active role in initiating their limited in-person interactions. As she states, "I kinda forced him to see me anyways." She sees this in-person interaction as being more "personal" and a way for her to ask questions "on the fly." Later in the interview, Cassandra states that she would have liked to have met with her mentor even more "I think forcing him to see me more, that probably would have been helpful, and probably like picking his brain more." Cassandra describes her partner as having a similarly distant relationship to her mentor.

\section{Accumulating questions that he may not be expecting}

Now we discuss one pattern of interaction that came out in the mid-semester interview. Cassandra had many questions related to the nature of their research project, specifically about why they were creating visualizations of simulations, how the simulations were created, and what they expected to learn. She saw her mentor as the source of answers to these questions. Cassandra then described how the process by which her questions were answered involved accumulating many questions over time and asking them all at once.

Interviewer: Have you started working with you research mentor yet?

Cassandra: Yes...But um, but yeah, I saw him last week on like Friday and just kinda talked his ear off for a second. But, (laughs) but um, we'll be meeting with him on Wednesday... [Cassandra lists several questions about the details of their project]... I guess what I would want to know the most is, well, how did we first like make a simulation for how the matter was distributed. You know? That to me is really interesting. And the program that we're, the initial conditions were put into, or like, what? How did they write such a program? I don't know, that's really exciting. And why did they choose this one as opposed to-'cause there's a bunch of them out there. Um, and how does it compare to what we know? You know what I mean?... Or the whole thing about dark matter like um, like we know, we don't really know what dark matter is. Do we? So how did they apply that to their model? Like how did they apply that to their simulation? How did they get a number? How did they quantize the distribution of dark matter in the universe? Like we know, so it's all really interesting, those are all questions we'll be asking him on Wednesday. I hope he's ready.

Cassandra describes how the previous Friday, she had talked his ear off with her questions, and then names a long list of other questions she is currently grappling with, that she intends to ask her mentor about on Wednesday. Her wording of the phrases talked his ear off and "I hope he's ready" positions herself as taking an active role in seeking out answers to her questions, and perhaps that her mentor does not expect her to be asking them. This kind of relationship has a very different feel from the relationship between Neil and his mentor, who intentionally anticipated students' questions, proactively checked in with them, and made himself available to answer them.

\section{B. Engagement in disciplinary activities}

\section{Limited purposefulness and connectedness}

In the midsemester interview, there is evidence that Cassandra is not getting to see the connections between her work and other scientific activities, namely, how it connects to prior work generating the simulated data.

Interviewer: How do you feel like it's going? Cassandra: Um. So far so good, although we're still not- one thing we're not really clear about, and that's uh, we're taking theoretical [simulated] data and we're basically making it very visual. But we don't-it hasn't been made clear to us, the simulation that the data's been run through... we don't really have an understanding yet of what, like the initial conditions were for the data that we got and then um, I guess there's different simulations you can run these conditions through, and so why he chose this one as opposed to others. So we're gonna talk to him about that on Wednesday.

Cassandra points out not knowing what the initial conditions are for the data, or how it connected to prior scientific activity of generating the data. In particular, she does not want to just know what the initial conditions were, but also how those were chosen. We argue that she wanted to connect the simulated data connected to some theoretical understanding that led to the initial conditions. 
To some extent, the activities that Cassandra engaged in within her research experience were linked. In both the mid- and postinterview, the visualizations are directly connected to the data that had been generated. Had Cassandra been prompted to describe the subactivities of generating visualizations, she likely could have described more connected activities at a smaller grain size. In the postinterview, she describes how visualizing data led to her identifying "a possible bug," and connects that to a (future) activity, examining more visualizations to "see if the bug is real or... something else," and then figuring out how to fix the code. But though Cassandra saw day-to-day activities as connected to one another, she struggled to connect these activities to other research activities.

Cassandra also had questions about the broader set of research activities. When asked about what would count as "success" to her in the project (during the mid-interview), she said it would be having an understanding of the importance of their work:

Interviewer: What would have to happen for you to be like, this semester went well in lab?

Cassandra: Why are we putting it into pretty pictures? Like how is that gonna help us?... Understanding the bridge between numbers and something you can look at. I mean, that would be a success. Seeing the fruits of your labor, I don't know. Cause why do we do that? Why are we creating this model of something we'll never see? What, how is that going to add to the scientific community? You know?...It would be interesting to see if we learn something from seeing this data.

At the start of this excerpt, we again see limited connectedness; Cassandra explicitly asks what the "bridge" is between the simulated data and her visualization work. Cassandra also describes a desire to understand the scientific purpose of this work. She specifically asks "how is that going to add to the scientific community?" This illustrates that she understands that research should be relevant to the scientific community, and she has some sense that her work is; however, she does not understand the details of what her work could contribute to the community. At the end of the statement, she is curious about whether or not they will "learn something from seeing this data." Here, Cassandra is not only asking what's the purpose of the endeavor, but also how their work might connect to some kind of scientific insight.

In the postinterview, Cassandra still states that she does not understand the purpose of her research activities or how they connect to initial conditions. As she describes "a part of research is to look at data and visualize it." This statement is more abstractly about the nature of research, rather than directly tied to her project.

\section{Linking joint work to engagement in disciplinary activities}

We argue that in Cassandra's case, her limited sense of purposefulness and connectedness of scientific activities stemmed in part from features of joint work between Cassandra and her mentor. Cassandra's interactions with her mentor were primarily limited to email exchanges and occasional in-person meetings that she had to seek out herself. Unlike Neil and Frank, Cassandra had limited opportunities to co-work with her mentor. Cassandra explicitly connects being limited to email exchanges to not having questions answered in her postinterview: "I just felt email exchanges were impersonal, and I didn't-if I had questions, you know on the fly, you can't really do that through email." This setup led to her accumulating questions over time and then asking them to her mentor all at once. We argue that having fewer opportunities to ask these questions, rather than having immediate feedback while working alongside mentors, led to Cassandra having a low sense of connectedness and purposefulness.

While we characterize Cassandra's research experience as low connectedness and purposefulness, we do not mean to imply that her research experience was not valuable. She still learned skills (e.g., computer programming) that would likely create new opportunities for her to participate in future physics experiences. She also asked important questions about her projects' purposefulness and connectedness, which we find valuable. However, her bids were not taken up by her mentor, which limited her access to learning the connectedness and purposefulness of her work (and thus limited her deeper participation, as we have modeled here). In other cases, such questioning could likely lead to a student in developing deeper participation in physics practice.

In the post-interview, Cassandra still had not gained a sense of connectedness and purposefulness. One might wonder why this was the case, given that she was so proactive about saving up questions and asking them. The activity of asking questions in meetings occurred as a separate activity from her day-to-day work on the visualizations. We believe that the discursive separateness of her engagement in day-to-day activities and discussing a broader purpose and theory likely contributed to her sense of a lack of connection between her day-to-day activities and the insights about the purpose of her work (and its connections to previous work) she may have gained during question-and-answer sessions.

The asynchronous workflow was also another contributing factor to Cassandra's mentor being unresponsive to Cassandra's questions. Cassandra's role on the project required her to develop expertise using a visualization package that her mentor did not know how to use, so she and her partner learned from online resources rather than their mentor, and had fewer opportunities to coordinate activities. Allowing mentees to develop complementary expertise to the mentor does not necessarily lead to 
TABLE I. Summary of data streams for each of the three case studies featured in this paper.

\begin{tabular}{|c|c|c|c|c|}
\hline & Pre & Post/1-Year & Mentor Int & $\begin{array}{c}\text { Level of } \\
\text { connectedness or } \\
\text { purposefulness }\end{array}$ \\
\hline Frank & $\mathrm{X}$ & $\mathrm{X}$ & $X$ & High \\
\hline Neil & $\mathrm{X}$ & $\mathrm{X}$ & $X$ & Mixed \\
\hline Cassandra & $\mathrm{X}$ (mid) & $X$ & & Low \\
\hline
\end{tabular}

separation of day-to-day activities; the mentor would need to more deliberately structure activities to have opportunities for immediate feedback-for instance, by using Neil's mentor's strategy of working one room over and regularly checking in.

Cassandra's case reveals another form of LPP within physics research. As the mentee, Cassandra played a more active role in facilitating interactions between students and mentors than Neil and Frank needed to do. However, having fewer opportunities to engage in the kinds of shared task alignment or joint attention with a mentor that characterized Frank's and Neil's experiences still led her to see the physics research activities as not fully connected nor purposeful. She also proactively asked questions about connectedness and purposefulness, but her mentor did not engage with those questions. Thus, another form of LPP can involve making bids for mature practice, but having those bids denied by a mentor. Based on this analysis, we find that Cassandras research experience resulted in limited opportunities to engage in physics practice.

\section{DISCUSSION}

In this paper, we illustrated various forms of legitimate peripheral participation in the physics research community as it played out in undergraduate physics research experiences. Using student interviews, we analyzed the extent to which students engaged in physics practice, defining a scientific practice as a set of activities which are purposeful and connected. Drawing from situated learning theory, in which engagement in activities depends on the setting, relationships, and joint activities, we outlined aspects of the research projects' structure and patterns of interaction with mentors that contributed to the extent to which-and the ways in which-students saw activities as purposeful and connected. We have summarized the cases in Table II and illustrated these connections in Fig. 2.

Although much work has focused on students' engagement in particular science activities such as argumentation $[63,64]$, developing mechanistic accounts of phenomena [65], and scientific reasoning [66], little work has focused on how students understand the purpose of those activities or their connection to other activities. We attend to activities at a meta-level, focusing on how these activities fit together in service of a broader purpose. By applying Ford's framework to cases of undergraduate research experiences, we hope to give research mentors more tools to be responsive to students seeking connectedness and purposefulness in their work.

Within this paper, we have used student interviews as a primary data source to develop claims about the extent to which their participation in activities were purposeful and connected. We take students' accounts of how their research activities were connected and purposeful as evidence that their participation in physics practice shifted (and thus, that learning happened). We expect their perspectives on research activities to differ from the perspectives of others in the community, including more central participants. For example, a mentor might make deliberate attempts to connect a research experience to a scientific purpose, but a student may not see it that way. Both perspectives matter in judging one's position in a communities of practice. However, we choose to focus on students because it is not clear that students learn everything that mentors intend

TABLE II. Summary of connectedness, purposefulness, and joint work across the three case studies.

\begin{tabular}{|c|c|c|c|}
\hline & Connectedness & Purposefulness & Joint work \\
\hline Frank & $\begin{array}{l}\text { Articulated connections } \\
\text { between theoretical } \\
\text { and computational } \\
\text { aspects of project. }\end{array}$ & $\begin{array}{l}\text { Articulated that the purpose of the } \\
\text { research project was to } \\
\text { confirm/disconfirm a hypothesized } \\
\text { mechanism for an empirical } \\
\text { observation. }\end{array}$ & $\begin{array}{l}\text { Project was laid out step by } \\
\text { step by mentor. Oscillated } \\
\text { between working independently } \\
\text { and co-coordinated activities. }\end{array}$ \\
\hline Neil & $\begin{array}{l}\text { Articulated connections } \\
\text { between the circuit theory, } \\
\text { circuit design, and data } \\
\text { collection. }\end{array}$ & $\begin{array}{l}\text { Articulated how activities helped the } \\
\text { lab's experiment, but not the } \\
\text { purpose of the lab's experiment. }\end{array}$ & $\begin{array}{l}\text { Project described as "build widget," } \\
\text { "test widget." When working } \\
\text { independently, mentor would } \\
\text { check in on them and be } \\
\text { available to answer questions. }\end{array}$ \\
\hline Cassandra & $\begin{array}{l}\text { Limited connectedness } \\
\text { between theory and the } \\
\text { starting assumptions designed } \\
\text { into the simulation. }\end{array}$ & $\begin{array}{l}\text { Limited sense of how the work } \\
\text { would help the scientific } \\
\text { community. }\end{array}$ & $\begin{array}{l}\text { Worked asynchronously, } \\
\text { with infrequent mentor } \\
\text { communications. Accumulated } \\
\text { questions over time. }\end{array}$ \\
\hline
\end{tabular}



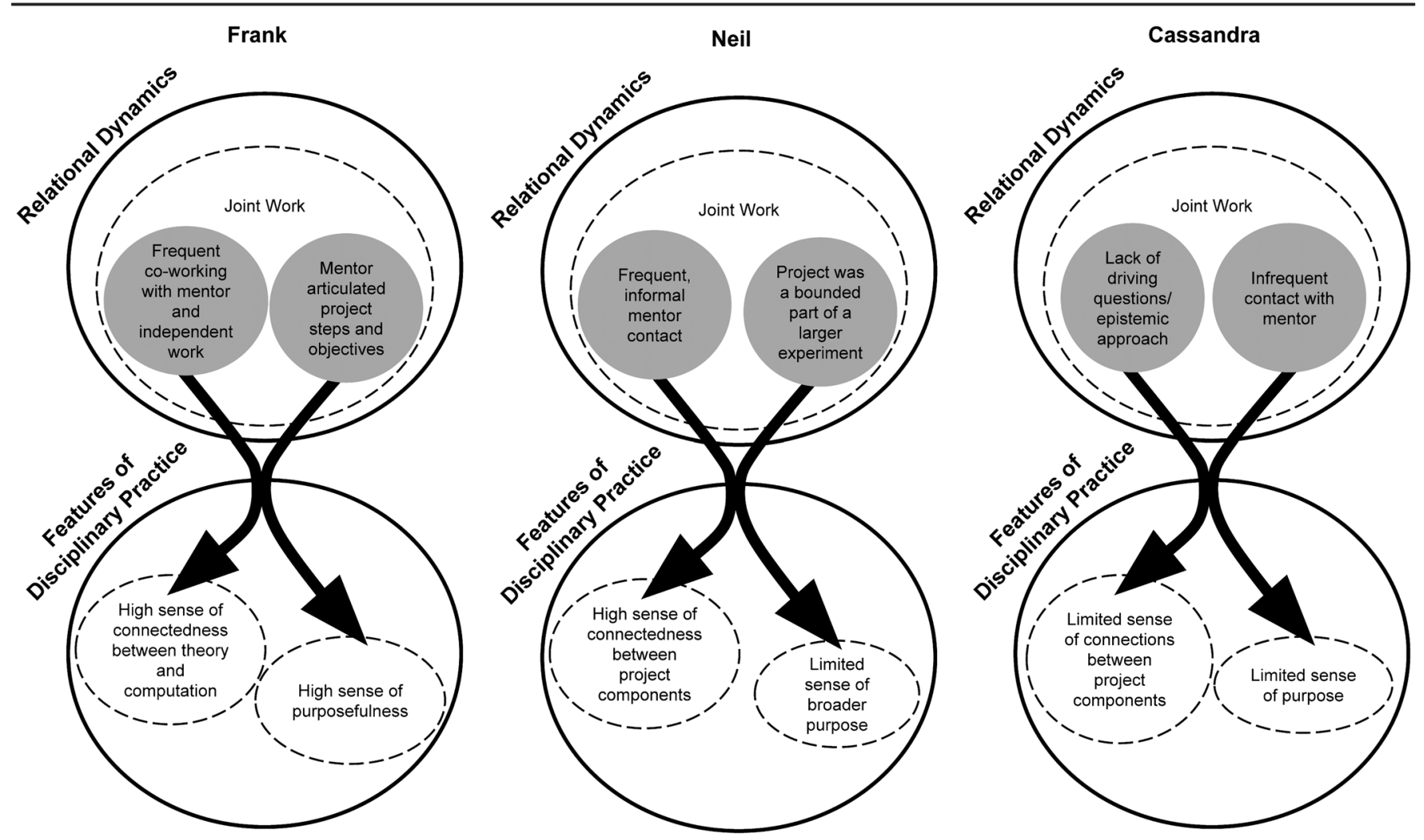

FIG. 2. Summary of connectedness, purposefulness, and joint work within the analytic framework.

for them to learn. Future studies of legitimate peripheral participation within UREs would benefit from analyzing across these perspectives.

We cannot use these three case studies to build generalizations within this population of students or across populations of students [56]. Developing claims about how these results might generalize to different populations of students would be an important area for future work. However, we can use this work to build theoretical generalizations about how project form and structure and patterns of interaction impact connectedness and purposefulness (as illustrated in Fig. 1). In the next few sections, we begin this work.

\section{A. Our analytical approach helps us build claims about how joint work can support engagement in a scientific practice}

Prior research on undergraduate research has identified the kinds of research activities that students engage in when doing UREs. However, this work has not used a communities of practice framework to take a fine-grained look at how the structure of activities supports different kinds of learning. Our research complements this prior work by showing some of the finer-grained details of what engagement in UREs looks like.

While surveys can capture the extent to which students engaged in specific scientific activities, interview-based and other qualitative research allows us to characterize the extent to which and ways in which those scientific activities were connected and purposeful. Consider this item from the undergraduate research questionnaire [7]:

\section{Data analysis is something I can do.}

Many students might agree with this item, but the item does not capture the extent to which their participation in the activity of data analysis is connected to other activities, or whether the student understood the scientific purpose. We see those features of scientific activities as being essential to doing science [37]. To make this example more concrete, Cassandra and Neil would likely agree with this statement. But the details of their participation differ. Neil's engagement in data analysis directly stemmed from measurements he had taken using the circuit he had built, and he saw his work as helping the research group decide whether some unexpected results of previous experiments were caused by temperature fluctuations in the room. In contrast, Cassandra analyzed visualizations of the simulated data, but she still had many questions about where the data came from and why her work was important. We see these details of knowing why a particular form of data analysis makes sense for a given set of data and having an understanding of how the data was produced from an instrument (or simulation) as important aspects of doing science that would likely impact students' long-term engagement. 
We do think it would be possible to design survey items that assess the degree to which students view scientific activities as purposeful or connected, but interviews leave room for exploring the nature of that purposefulness and connectedness. Consider the survey item "I understand the broader purpose of the experiments I am conducting" [67]. Frank would likely agree with that item, but his survey response would not allow us to examine how his participation in activities "hangs together" and the sensibility and coherence of the logic behind those connections, from both Frank's and a researcher's perspective. In a different vein, Neil might agree or disagree with that item, depending on whether he was thinking about the purpose of his project within the lab, or the purpose of the lab's experiments in the broader physics research community.

Analysis of interviews allows us to characterize these different forms of LPP and how they might impact students' future trajectories into the scientific community. Going back to the example of Neil and Cassandra's different experiences with data analysis, Neil has engaged in data analysis as connected to instrument development and a driving question. Even though he does not have full understanding of the broader purpose of the lab's experiment, having these opportunities for understanding connectedness and purposefulness of activities would likely support deeper participation. In contrast, Cassandra's experience with data analysis was disconnected from the generation of simulated data and the purposes of simulating that data (i.e., less access to scientific practice). Cassandra's participation in the physics research community of practice is more limited, and there are fewer clear avenues for deeper participation in the future.

An area for future study would be to collect and analyze in situ data of students and mentors to see how connectedness and purposefulness are supported within interactions. Our interviews suggest where one might focus attention in such analyses, such as how students' questions are addressed and the spatial orientation of students and mentors.

\section{B. Prevalence of lack of broader purpose}

Across our broader set of data, many students did not describe having regular opportunities to contextualize the set of research activities within the broader scientific purpose. Neil stated that he was unfamiliar with the broader purpose of the research lab's activities. He later stated that this stemmed from not having taken advanced coursework. Bounded senses of purpose of research activities likely stemmed from multiple factors such as limited amount of time and level of background knowledge. We believe that this infrequent examination of the "10000 ft view" of research is also fairly common in science; while focused on wiring a detector, debugging code, or "cleaning" data, a researcher might find little time to reflect on the broader purpose of their work - though of course they are capable of doing so.
We also note that a lack of sense of broader purpose is not necessarily a bad thing. Mentors are managing multiple goals and constraints, such as limited time, wanting students to have an enjoyable experience, and wanting to make research progress [5]. Scaffolding students' understanding of the broader purpose might not rise to the top of students' and mentors' goals. Neil's mentor, and likely other members of their subdiscipline, would probably not mind that Neil did not understand the broader purpose. In a later part of the interview, Neil suggested that because he did not have to understand a lot of background knowledge, he felt capable of doing research. In contrast, Cassandra's lack of understanding of the broader purpose of her activity made her consider switching into another area of physics research. So, while students' engagement in connectedness and purposefulness interact with their satisfaction in ways that likely impact students' long-term trajectories, Cassandra and Neil illustrate how those interactions vary from student to student.

\section{Practical implications for UREs}

This work demonstrates how the design of research experiences and interactions between mentors and mentees can impact students' participation in scientific practice. This points to features to attend to when supporting undergraduate researchers. We argue that URE mentors should attend to the ways in which scientific activities are meaningful with respect to one another and to a broader scientific purpose, and the logic behind how activities are coordinated. For example, mentors can design research experiences with an overarching flow in mind, and support students in understanding why this flow is sensible. We acknowledge that seeing activities as connected and purposeful takes time, so it is important to think ahead about how activities might come to be connected to one another and to a scientific purpose in coherent ways. Such deliberation may increase students' opportunities to engage in a scientific practice.

While we recommend that mentors design projects with an overarching flow in mind, we caution mentors to be mindful about the extent to which they prescribe student participation. If followed too rigidly, a step-by-step approach could strip away student agency and block opportunities for critique. It is up to the mentor to be mindful that students are understanding the connections between those steps, rather than just following directions.

Designers of environments such as 299B should also consider giving students opportunities to reflect on connectedness and purposefulness. Within this environment, course instructors could support students in drawing out connections between individual activities and a scientific purpose.

Finally, we also note how the environment and workflow between mentors and mentees enables more responsive relationships which ultimately support connectedness and 
purposefulness. We argue that it is not enough to just address students' concerns as they come up. Mentors should also consider how their setting and workflow might lower the barrier to starting and maintaining conversations. Our analytical framework illustrates that the nearby presence of Neil's mentor supported Neil's participation, even though they were working on different tasks. We suggest that mentors could deliberately sit in the same room as mentees over some periods of time so mentees can ask questions as they come up. In working together, mentors could invite reflection on the broader purpose of their work or discussion about how one activity feeds into another. Students' construction of these answers likely requires dialogue with people who have disciplinary expertise in that project area. Arranging work patterns to be more collaborative would support that. Work by Museus suggests that mentors proactively making support available and fostering more collective working environments can be especially beneficial to students of color [68]. Our analyses illustrate how challenging it is for students to gain an understanding of connectedness and purposefulness of scientific activities on their own, and so mentors should explicitly support this big-picture framing of their project.

\section{Future studies of equity considerations of connectedness, purposefulness, and joint work}

This work is part of a larger study in which we are trying to understand shifts in students' participation in physics for the purpose of knowing how to better create physics pathways for students who have been historically marginalized. In future work, we will study aspects of students' racialized or gendered identities as they interact with joint work and students' satisfaction with connectedness and purposefulness of their research. How interactions become gendered and racialized is an important area of study. While our analyses have not included race and gender explicitly, we do believe they are at play in our data, and we think our analyses motivate future work on race and gender in studies of UREs. Research has shown that while UREs can be particularly beneficial to students from underrepresented groups [2], not all students have access to participating in research experiences [69]. This motivates work toward understanding the interactions and settings in which disciplinary learning occurs, such as undergraduate research experiences [70,71].

If it were commonplace that connectedness and purposefulness were missing from UREs we would expect students to react differently. Neil and Cassandra illustrate variations in the degree to which students care (or not) about purposefulness at multiple grain sizes. Neil seemed satisfied with understanding the local purpose of his research within the research group, and not understanding the broader purpose of the lab. Within Cassandra's interview, she was emphatic about wanting to understand how her work was connected to prior work, and what purpose it could serve within the scientific community. It is plausible that this would unfairly marginalize students who value their working having relevance within a scientific community. Other research suggests this may be the case for women and students of color [70,71]. For example, Tobias describes the lack of a "narrative thread" and context as being one reason why students' leave physics [71]. Depending on how well students' desires to understand connectedness and purposefulness fit with what is afforded by the projects, they might have positive or negative experiences in UREs that could impact their long-term trajectories.

We also believe that mentoring behaviors such as leaving the burden on students to schedule regular meetings and ask questions would disproportionately favor more aggressive students (aligned with stereotypically male socialization [70]) and students who have greater comfort talking to faculty (e.g., students from college-educated families, and students of higher socioeconomic status [72].) We encourage research mentors to reflect on how their forms of communication might privilege students who are white, male, and high socioeconomic status, and consider how they might lower the barrier to interactions. For example, creating dedicated time and space to co-work with a mentee, as we saw in Frank's case, would support mentors in being more responsive to mentee's questions and ideas. In future work, we plan to discuss these features that impact students' long-term trajectories and consider how their histories and identities are interacting with the way they experience physics research.

\section{E. Future studies of students' long-term engagement in physics}

Future work will also longitudinally study how participation in UREs impacts students' long term participation in the physics research community of practice.

While we have conceptualized participation in the physics research community of practice as centered around the connectedness and purposefulness of activities, we value other learning outcomes as well. Future work should consider a broader definition of participation, including students' conceptualizations of the physics community, affective dimensions such as their sense of satisfaction, and how they are positioned by mentors and peers as belonging (or not) within the discipline. Future work will describe the nuanced ways that these additional aspects bear on students' long-term participation in the physics research community.

We also find it worthwhile to broaden our view of what it means to participate in the physics research community. This is motivated in part by Wenger's study of claims processors, in which he describes regular office birthday celebrations as important to the local community of practice. In our own interviews, we similarly found that physics communities participated in activities that one 
might not think of as central to the physics discipline, but that still mattered for students' engagement. For example, bonding over video games or other aspects of "geeky" culture are not particularly important to constructing physics knowledge, but not participating in such activities can negatively impact students' access to physics. Other students described attending regular social outings with their research groups, or talking with research mentors about mutual hobbies. We see these activities as part of what membership in the physics community entails, but they have not been as foregrounded in conceptualizations of the domain.

Finally, future work will also explore how students' participation in physics is mediated by race, gender, age, and other dimensions of student identities. Several interviews suggest that students are noticing and contending with normative physics identities of who is typically a physics major. It would be worthwhile to analyze the ways students navigate normative physics identities and consider how students from diverse backgrounds are differentially impacted. Understanding how the physics research community marginalizes students would be an important step toward fostering more inclusivity in physics.

\section{ACKNOWLEDGMENTS}

We thank Dimitri Dounas-Frazer, Ayush Gupta, Christina Krist, Enrique Suarez, and members of the UMD Physics Education Research Group for their feedback, as well as thoughtful anonymous reviewers. This material is based upon work supported by the National Science Foundation under Grant No. DUE-1245590 and the UMD Physics Department Office of Student and Educational Services. Publication of this article was funded by the University of Colorado Boulder Libraries Open Access Fund.
[1] American Physical Society, Undergraduate Research Statement (2014), https://www.aps.org/policy/statements/14_1 .cfm.

[2] S. Olson and D. G. Riordan, Engage to Excel: Producing One Million Additional College Graduates with Degrees in Science, Technology, Engineering, and Mathematics. Report to the President (Executive Office of the President, Washington, DC, 2012).

[3] B. F. Albanna, J. C. Corbo, D. R. Dounas-Frazer, A. Little, A. M. Zaniewski, P. V. Engelhardt, A. D. Churukian, and N.S. Rebello, Building classroom and organizational structure around positive cultural values, AIP Conf. Proc. 1513, 7 (2013).

[4] D. R. Dounas-Frazer and D. L. Reinholz, Attending to lifelong learning skills through guided reflection in a physics class, Am. J. Phys. 83, 881 (2015).

[5] S. Laursen, A.-B. Hunter, E. Seymour, H. Thiry, and G. Melton, Undergraduate Research in the Sciences: Engaging Students in Real Science (John Wiley \& Sons, New York, 2010).

[6] E. Seymour, A.-B. Hunter, S. L. Laursen, and T. DeAntoni, Establishing the benefits of research experiences for undergraduates in the sciences: First findings from a three-year study, Sci. Educ. 88, 493 (2004).

[7] R. Taraban and E. Logue, Academic factors that affect undergraduate research experiences, J. Educ. Psychol. 104, 499 (2012).

[8] D. Lopatto, Survey of undergraduate research experiences (SURE): First findings, Cell Biol. Educ. 3, 270 (2004).

[9] R. E. Landrum and L. R. Nelsen, The undergraduate research assistantship: An analysis of benefits, Teach. Psychol. 29, 15 (2002).
[10] S. R. Gregerman, J. S. Lerner, W. von Hippel, J. Jonides, and B. A. Nagda, Undergraduate student-faculty research partnerships affect student retention, Rev. High. Educ. 22, 55 (1998).

[11] A. E. Barlow and M. Villarejo, Making a difference for minorities: Evaluation of an educational enrichment program, J. Res. Sci. Teach. 41, 861 (2004).

[12] Business-Higher Education Forum (BHEF), The U.S. STEM Undergraduate Model: Applying System Dynamics to Help Meet President Obamas Goals for One Million STEM Graduates and the U.S. Navys Civilian STEM Workforce Needs, 2013, http://www.bhef.com/sites/ default/files/BHEF_2013_stem_undergrad_model.pdf.

[13] A.-B. Hunter, S. L. Laursen, and E. Seymour, Becoming a scientist: The role of undergraduate research in students' cognitive, personal, and professional development, Sci. Educ. 91, 36 (2007).

[14] R. Taraban and R. L. Blanton, Creating Effective Undergraduate Research Programs In Science: The Transformation from Student to Scientist (Teachers College Press, New York, NY, 2008).

[15] N. G. Holmes and C. E. Wieman, Examining and contrasting the cognitive activities engaged in undergraduate research experiences and lab courses, Phys. Rev. Phys. Educ. Res. 12, 020103 (2016).

[16] D. Lopatto and S. Tobias, Science in solution: The impact of undergraduate research on student learning (Council on Undergraduate Research, Tuscon, AZ, 2010).

[17] A. M. Byars-Winston, J. Branchaw, C. Pfund, P. Leverett, and J. Newton, Culturally diverse undergraduate researchers' academic outcomes and perceptions of their research mentoring relationships, Int. J. Sci. Educ. 37, 2533 (2015). 
[18] H. Thiry and S. L. Laursen, The role of student-advisor interactions in apprenticing undergraduate researchers into a scientific community of practice, J. Sci. Educ. Technol. 20, 771 (2011).

[19] S. H. Russell, M. P. Hancock, and J. McCullough, Benefits of undergraduate research experiences, Science 316, 548 (2007).

[20] J. A. Harsh, A. V. Maltese, and R. H. Tai, Undergraduate research experiences from a longitudinal perspective, J. Coll. Sci. Teach. 41, 84 (2011).

[21] M. Malachowski, The mentoring role in undergraduate research projects, Council on Undergraduate Research Quarterly 12, 91 (1996).

[22] M. C. Linn, E. Palmer, A. Baranger, E. Gerard, and E. Stone, Undergraduate research experiences: Impacts and opportunities, Science 347, 1261757 (2015).

[23] M. J. Ford and E. A. Forman, Chapter 1: Redefining disciplinary learning in classroom contexts, Rev. Res. Educ. 30, 1 (2006).

[24] J. Lave and E. Wenger, Situated Learning: Legitimate Peripheral Participation (Cambridge University Press, Cambridge, England, 1991).

[25] E. Wenger, Communities of Practice: Learning, Meaning, and Identity (Cambridge University Press, Cambridge, England, 1998).

[26] M. J. Ford, Educational implications of choosing "Practice" to describe science in the next generation science standards, Sci. Educ. 99, 1041 (2015).

[27] P. W. Irving and E. C. Sayre, Conditions for building a community of practice in an advanced physics laboratory, Phys. Rev. ST Phys. Educ. Res. 10, 010109 (2014).

[28] E. W. Close, J. Conn, and H. G. Close, Becoming physics people: Development of integrated physics identity through the Learning Assistant experience, Phys. Rev. Phys. Educ. Res. 12, 010109 (2016).

[29] I. Rodriguez, R. M. Goertzen, E. Brewe, and L. H. Kramer, Developing a physics expert identity in a biophysics research group, Phys. Rev. ST Phys. Educ. Res. 11, 010116 (2015).

[30] R. M. Goertzen, E. Brewe, and L. Kramer, Expanded markers of success in introductory university physics, Int. J. Sci. Educ. 35, 262 (2013).

[31] S. Traweek, Beamtimes and Lifetimes (Harvard University Press, Cambridge, MA, 2009).

[32] A. Kelly, Design research in education: Yes, but is it methodological?, J. Learn. Sci. 13, 115 (2004).

[33] B. Barron, When smart groups fail, J. Learn. Sci. 12, 307 (2003).

[34] B. Barron, Achieving coordination in collaborative problem-solving groups, J. Learn. Sci. 9, 403 (2000).

[35] B. Kirshner, Guided participation in three youth activism organizations: Facilitation, apprenticeship, and joint work, J. Learn. Sci. 17, 60 (2008).

[36] B. Rogoff, Developing understanding of the idea of communities of learners, Mind Cult. Activ. 1, 209 (1994).

[37] L. K. Berland, C. V. Schwarz, C. Krist, L. Kenyon, A. S. Lo, and B. J. Reiser, Epistemologies in practice: Making scientific practices meaningful for students, J. Res. Sci. Teach. 53, 1082 (2015).
[38] J. Rouse, Practice theory, Handbook of the Philosophy of Science (Elsevier, Dordrecht, 2007).

[39] N. R. Council et al., A Framework for K-12 Science Education: Practices, Crosscutting Concepts, and Core Ideas (National Academies Press, Washington, DC, 2012).

[40] P. Bell, L. Bricker, C. Tzou, T. Lee, and K. Van Horne, Exploring the science framework: Engaging learners in scientific practices related to obtaining, evaluating, and communicating information, Sci. Teach. 36, 17 (2012).

[41] B. J. Reiser, L. K. Berland, and L. Kenyon, Engaging students in the scientific practices of explanation and argumentation, Sci. Teach. 79, 34 (2012).

[42] C. Passmore, J. S. Gouvea, and R. Giere, in International Handbook of Research in History, Philosophy and Science Teaching (Springer, New York, 2014), pp. 1171-1202.

[43] J. Osborne, Teaching scientific practices: Meeting the challenge of change, J. Sci. Teach. Educ. 25, 177 (2014).

[44] The Compass Project is a student-led program dedicated to improving equity in the physical sciences through several activities, including courses and a summer program for first-year undergraduate students. The Compass Project is one of eight institutions in the Access Network.

[45] P. R. Gandhi, J. A. Livezey, A. M. Zaniewski, D. L. Reinholz, and D. R. Dounas-Frazer, Attending to experimental physics practices and lifelong learning skills in an introductory laboratory course, Am. J. Phys. 84, 696 (2016).

[46] A. Little, STATUS: A Report on Women in Astronomy (American Astronomical Society, Washington, DC, 2015).

[47] H. R. Bernard, Social Research Methods: Qualitative and Quantitative Approaches (Sage Publications, Newbury Park, CA, 2012).

[48] S. Scribner, Situating the experiment in cross-cultural research, The Developing Individual in a Changing World (Walter de Gruyter, Berlin, 1976), Vol. 1, p. 310.

[49] H. Becker and B. Geer, Participant observation and interviewing: A comparison, Hum. Organ. 16, 28 (1957).

[50] B. Jordan and A. Henderson, Interaction analysis: Foundations and practice, J. Learn. Sci. 4, 39 (1995).

[51] S. J. Derry, R. D. Pea, B. Barron, R. A. Engle, F. Erickson, R. Goldman, R. Hall, T. Koschmann, J. L. Lemke, M. G. Sherin and B. L. Sherin, Conducting video research in the learning sciences: Guidance on selection, analysis, technology, and ethics, J. Learn. Sci. 19, 3 (2009).

[52] R. A. Engle, F. R. Conant, and J. G. Greeno, Progressive refinement of hypotheses in video-supported research, Video Research in the Learning Sciences (Routledge, New York, NY, 2007), p. 239.

[53] S. J. Tracy, Qualitative quality: Eight "Big-Tent" criteria for excellent qualitative research, Qualitative Inquiry 16, 837 (2010).

[54] J. P. Spradley, The Ethnographic Interview (Waveland Press, Boulder, CO, 1979).

[55] H. B. Carlone, Identity Construction and Science Education Research (Springer, New York, 2012), pp. 9-25. 
[56] M. Eisenhart, Generalization from qualitative inquiry, Generalizing from Educational Research (Routledge, New York, NY, 2009), p. 51.

[57] A. D. Robertson, R. E. Scherr, and S. B. McKagan, Paradigms in physics education research, arXiv:1307.4135.

[58] R. Hall, Strategies for video recording: Fast, cheap, and (mostly) in control, Guidelines for Video Research in Education: Recommendations from an Expert Panel (Data Research and Development Center, Chicago, IL, 2007), p. 4.

[59] F. Erickson, Definition and analysis of data from videotape: Some research procedures and their rationales, Handbook Complementary Methods Education Research (Lawrence Erlbaum Associates, Washington, DC, 2006), Vol. 3, p. 177.

[60] R. Hall, in Handbook of Research Design in Mathematics and Science Education, edited by A. E. Kelly and R. Lesh (Lawrence Erlbaum, Mahwah, NJ, 2000).

[61] A. L. Brown and J.C. Campione, Psychological Theory and the Design of Innovative Learning Environments: On Procedures, Principles, and Systems (Lawrence Erlbaum Associates, Inc., Mahwah, NJ, 1996).

[62] F. Erickson, Communicating in the Classroom (Academic Press, New York, 1982).

[63] M. P. Jimenez-Aleixandre, A. B. Rodriguez, and R. A. Duschl, "Doing the lesson" or "doing science": Argument in high school genetics, Sci. Educ. 84, 757 (2000).

[64] D. Kuhn, Teaching and learning science as argument, Sci. Educ. 94, 810 (2010).

[65] R. S. Russ, R. E. Scherr, D. Hammer, and J. Mikeska, Recognizing mechanistic reasoning in student scientific inquiry: A framework for discourse analysis developed from philosophy of science, Sci. Educ. 92, 499 (2008).

[66] D. Hammer, The variability of student reasoning, lecture 1: Case studies of children's inquiries, in Proceedings of the International School of Physics "Enrico Fermi", CLVI (IOS Press, Ohmsha, 1999, 2004), Vol. 156, pp. 279-300.

[67] B. G. Geller, P. Killion, W. Losert, and C. Turpen, Facilitating an authentic research experience in quantitative biology and biophysics (College Park, MD, 2015).

[68] S. D. Museus, The culturally engaging campus environments (CECE) model: A new theory of success among racially diverse college student populations, Higher Education: Handbook of Theory and Research (Springer, Dordrecht, 2014), pp. 189-227.

[69] S. 5 Hanshaw, D. R. Dounas-Frazer, and H. Lewandowski, Proceedings of the Physics Education Research Conference 2015, College Park, MD (AIP, New York, 2015), pp. 123-126.

[70] E. Seymour, Talking about Leaving: Why Undergraduates Leave the Sciences (Westview Press, Boulder, CO, 2000).

[71] S. Tobias, They're not dumb, they're different (Research Corporation, Tucson, AZ, 1990).

[72] C. E. Foor, S. E. Walden, and D. A. Trytten, "I Wish that I Belonged More in this Whole Engineering Group:" Achieving Individual Diversity, J. Eng. Educ. 96, 103 (2007).

Correction: The first name listed in the Acknowledgments section was misspelled and has been fixed. 